\title{
The Relationship Between Stress and Motivation in Pathological Gambling: a Focused Review and Analysis
}

\author{
Candice Biback $^{1,2} \cdot$ Martin Zack ${ }^{1,2}$
}

Published online: 8 July 2015

(C) Springer International Publishing AG 2015

\begin{abstract}
This article reviews key findings on stress, motivation, and pathological gambling (PG). Environmental and dispositional sources of stress that promote PG are described, along with effects of acute stressors on risk-based decisionmaking. Gambling itself has stress-like physiological effects, activating norepinephrine (NE), cortisol (CORT), and, in PG subjects, dopamine (DA). Chronic exposure to gambling could evoke neuroadaptations in these systems, and motivation to gamble in PG subjects may partly reflect an effort to restore homeostasis. Alpha-2 NE receptors tonically inhibit, and alpha-1 NE receptors augment, striatal DA release and hypothalamic-pituitary axis-mediated CORT response. Gambling-induced dysregulation of this circuitry, coupled with environmental and dispositional stressors, may lead to allostasis, sensitization, and disturbances in cognitive function that promote further gambling. Interventions that mitigate stress may therefore deter onset and restore control over compulsive motivation to gamble in individuals with PG.
\end{abstract}

Keywords Stress $\cdot$ Pathological gambling $\cdot$ Motivation · Allostasis $\cdot$ Cortisol $\cdot$ Alpha-2 NE receptor

This article is part of the Topical Collection on Gambling

Martin Zack

martin.zack@camh.ca

Candice Biback

candice.biback@camh.ca

1 Department of Pharmacology and Toxicology, University of Toronto, 1 King's College Circle, Toronto, ON M5S 1A8, Canada

2 Centre for Addiction and Mental Health, 33 Russell Street, Toronto, ON M5S 2S1, Canada

\section{Introduction}

\section{Definition of Stress}

In his seminal work, Hans Selye [1] defined stress as a nonspecific response of the body to environmental demand. Selye noted that stress entailed a deviation from physiological equilibrium or homeostasis, which represented the default state of the organism. He posited a general adaptation syndrome (GAS) whereby responses to environmental demand are managed by the hypothalamic pituitary adrenal (HPA) axis and sympathetic nervous system in the form of the fight-or-flight response. This response involves a tightly coordinated neurochemical cascade: perception of threat or challenge by the amygdala, activation and release of corticotropin releasing factor (CRF) from the hypothalamus, adrenocorticotropin hormone (ACTH) from the pituitary, and cortisol (CORT) from the adrenal cortex. At the same time, brain stem nuclei transmit catecholamines to limbic-striatal and frontal brain regions. When the challenge has passed, the system reverts to homeostasis. However, if the threat or challenge is very intense or persistent, the stress response may not fully extinguish, and the GAS could move into a chronic activation state. At this point, reversion to baseline may still occur fairly readily given a period of low environmental demand. Without such relief, the organism may progress to the final stage of the GAS, where the capacity for adaptive response to threat or challenge is lost - a condition known as allostasis: literally, a "new set point" in baseline stress level.

The GAS and its potential role in PG are depicted in Fig. 1 [2]. The figure shows that acute stress evokes alarm followed by a dip in arousal in the immediate aftermath of the stressor. Over time, baseline arousal shifts to a chronic readiness state termed resistance, which facilitates timely response to future stressors based on an ongoing history of stress. Eventually, the 


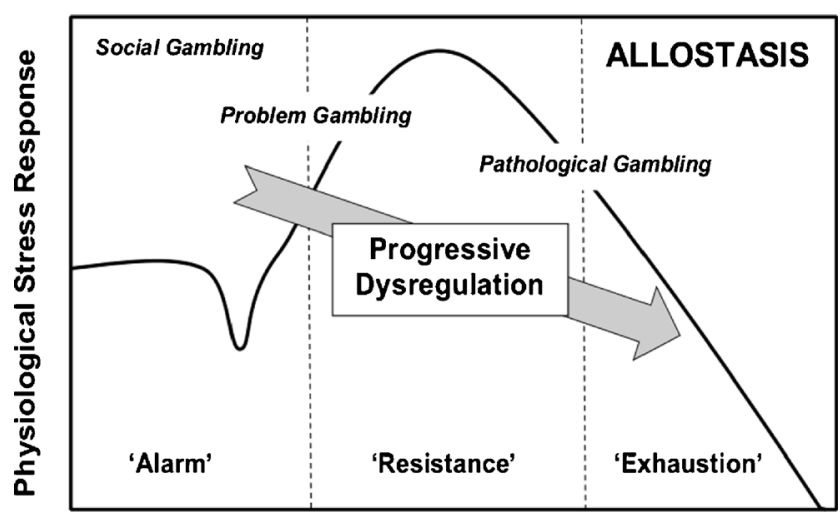

Time: Chronic Exposure to Gambling

Fig. 1 Selye's general adaptation syndrome of stress reactivity as applied to gambling. Social gambling=0 DSM-IV PG criteria; problem gambling $=1-4$ DSM-IV PG criteria; pathological gambling $=5-10$ DSM-IV PG criteria [cf. 47]

body's ability to maintain this elevated readiness state becomes depleted leading to the final stage of exhaustion, where allostasis severely impairs adaptive stress response.

The allostatic model has been applied to addictive drugs [3]. The model asserts that addiction involves transition to a state where the user needs the drug to restore homeostasis of the stress response system (i.e., addiction $\approx$ exhaustion). Other research emphasizes the role of stress in the initial development of addiction, whereby stress activates latent vulnerability to compulsive reward seeking in high-risk individuals [4], and in relapse, whereby stress reactivates dormant brain circuits that bias motivation toward addictive stimuli [5]. Thus, stress plays a critical role in the onset, progression, and relapse to addictive behavior in substance addiction.

In 2013, the American Psychiatric Association reclassified PG (as Gambling Disorder) from its earlier designation as an Impulse Control Disorder to a Substance-related and Addictive Disorder in the Diagnostic and Statistical Manual, DSM-5 [6]. This reclassification was partly based on research showing key parallels in the neurobiology of substance addiction and PG [7]. In line with this reclassification, accumulating evidence suggests that stress may play a pivotal role in the onset, progression, and reversion to PG [8-10].

The idea that stress, in the sense of excitement and arousal, is important to gambling is intuitive [11-13]. Selye referred to this positive form of activation as "eustress." More recently, Milkman and Sunderwirth [14] observed that stimulant drugs and gambling can both elicit this kind of "stress hormone high" (p. 135). The allostatic model of addiction further implies that neuroadaptations to chronic heavy gambling may directly promote the development and maintenance of PG [15]. Recent refinements in Selye's definition of stress help to explain why gambling, as opposed to other exciting activities (e.g., bungee jumping) should promote allostasis. Based on their review of the stress literature, Koolhaas et al. [16] proposed that "the term 'stress' should be restricted to conditions where an environmental demand exceeds the natural regulatory capacity of an organism, in particular situations that include unpredictability and uncontrollability" (p. 1291, italics added). Unpredictability and uncontrollability are integral to gambling, especially in activities linked with PG, like electronic gaming machines (EGMs) [17]. However, this does not explain why only $1-3 \%$ of individuals develop PG [18], even though most adults gamble, including on EGMs [19]. Therefore, other factors must contribute to a situation that "exceeds the natural regulatory capacity" of those who develop PG. These factors can be described as primarily environmental/situational or dispositional/developmental.

\section{Environmental/Situational Sources of Stress and Gambling}

Laboratory studies have documented the effects of acute stress on gambling-related behavior. Stress induced by anticipation of a self-revealing public speech impairs performance on the Iowa Gambling Task (IGT; which measures reward sensitivity and avoidance learning, cf. [20]), in healthy women who exhibit elevated CORT in response to the speech [21]. In a mixed gender sample, the Trier Social Stress procedure (which includes a demanding arithmetic task plus the speech), promotes risky decisions in response to wins in a lottery task, but only in subjects who display a significant increase in CORT [22•]. Exogenous CORT $(40 \mathrm{mg}$ ) increases risky decisions in healthy men, particularly when there is the prospect of a large reward [23]. Such findings suggest that glucocorticoids may decrease anxiety and increase reward sensitivity in healthy individuals. Accordingly, in healthy rats, exogenous corticosterone (equivalent to human CORT) promotes sensitivity to large rewards in a rodent version of the IGT (rat gambling task; rGT) [24]. Thus, HPA-mediated responses to stress can directly influence risk-based reward seeking and decisionmaking. By implication, disturbances in HPA function may promote disturbances in risk-based reward seeking and decision-making, which are hallmarks of PG.

Although stress and punishment engage similar neurophysiological substrates, they may not exert identical effects. The difference may reflect the unpredictable/uncontrollable nature of stress vs. the contingent relationship between an action and a punishing outcome. In healthy volunteers, threat of shock promotes risk avoidant choices and deceleration of heart rate (HR) when risk of loss is moderate and threat of shock is explicitly signaled on each decision trial [25]. In healthy male adolescents, pre-exposure to stress decreases willingness to place another bet on a gambling task but also reduces the difference in tendency to gamble after a win vs. a loss (known as "the reflection effect") [26•]. The decreased reflection effect also coincides with a smaller difference in HR 
deceleration after a loss vs. a win [26•]. These results highlight two important points: (1) effects of a stressor on decisionmaking in forced choice situations may not correspond to its effects on the decision to continue to gamble and (2) opting out may be an adaptive response to stress when the ability to decide how to bet based on physiological feedback is impaired. Previous work has shown that arousal can serve as an internal signal or somatic marker that guides decisions even without full awareness [27]. Factors that reduce the strength of somatic markers or impede their detection may thus impair adaptive decisions when gambling.

\section{Dispositional/Developmental Sources of Stress and Gambling}

Reactivity to a stressor varies greatly across individuals. The Yerkes-Dodson rule [28] states that, for complex tasks, there is an inverted-U relationship between baseline arousal and effects of a stressor on performance. Individuals with low baseline arousal perform best when environmental stress is high, as this shifts their arousal to the vertex of the inverted-U. In contrast, individuals with high baseline arousal perform best with low environmental stress, as they are already near the vertex of the inverted- $U$, so that additional stress leads to supra-optimal arousal and poorer performance. As a complex task, gambling should conform to the Yerkes-Dodson rule. Accordingly, healthy subjects with low resting HR make faster and more risky decisions on a gambling task and perceive risky options as less arousing and risky than do healthy subjects with high resting HR [29••]. Thus, "both trait and state arousal effects indicate an inverse relationship of arousal and risky behavior"(p. 498).

When chronic stress is high, the GAS predicts that individuals with high baseline arousal will be prone to sub-optimal/ risky decision-making due to increases in catecholamine and HPA responses that push them past their optimal level of arousal. In contrast, individuals with low baseline arousal may actually benefit from chronic stress in terms of their decision-making, at least during the early stages of chronic stress ("Alarm" and early "Resistance"; see Fig. 1). Regardless of initial baseline arousal however, the GAS predicts that prolonged exposure to stress will ultimately lead to deficient performance as the compensatory stress response begins to fail and allostasis takes hold (Fig. 1; "Exhaustion"). Under these circumstances, one may need to gamble to reverse deficient arousal and may need to create the conditions that facilitate this (e.g., set high stakes) [30]. In so doing, however, the individual sets the stage for an even greater demand for arousal, as allostatic baseline drops lower in the aftermath of gambling. This resembles the vicious cycle of escalating drug use and withdrawal in substance addiction.
By distorting perceived risk, psychiatric comorbidity can promote arousal in the absence of objective threat. Epidemiological data reveal high rates of PG in individuals with Panic or Generalized Anxiety Disorder [31]. In treatment-seeking PG samples, PTSD is also seen at very high rates [32]. The relatively higher rates of Generalized Anxiety and Panic vs. PTSD among individuals with PG in the general population [33] compared to treatment-seeking PG samples [34] may be related to the GAS. In Generalized Anxiety and Panic Disorder, CORT levels tend to be higher than in healthy controls $[35,36]$, indicating that these anxious individuals are still in the active compensatory phase of the GAS (Fig. 1; "Resistance"). However, in PTSD, CORT levels are consistently lower than in healthy individuals [37], indicating a progression to allostatic overload (Fig. 1; "Exhaustion"), although exceptions have been reported [38]. Gambling would be expected to cause supra-optimal arousal in individuals with Panic or Generalized Anxiety, promoting poor decisions (losses), escalating stress and progression toward allostasis. In those with PTSD, gambling may restore deficits in baseline arousal, temporarily relieving but ultimately worsening their pre-existing allostatic condition.

Among the strongest predictors of adult PTSD is childhood maltreatment [39]. Childhood maltreatment (neglect, abuse) is strongly linked with PG in the general population and is pervasive in treatment-seeking PG patients [40, 41]. Childhood maltreatment predicts severity and frequency of gambling problems, even after controlling for substance use and other psychosocial factors [42]. In individuals with probable PG, more than $19 \%$ meet DSM criteria for lifetime PTSD, especially among women [43]. This is $\sim 2.5$ times the lifetime rate of PTSD in the general population [44]. Almost 30 years ago, before PG became a widespread problem, Taber and colleagues [45] described PG patients as being in a "chronic state of negative affect related to cumulative life trauma and seemingly instrumental in potentiating addictive euphoria" (p. 71, italics added). The distinct reinforcing properties of gambling may explain why individuals who have already begun to experience allostasis escalate rapidly to PG.

\section{Acute and Chronic Effects of Gambling}

In an early study on the neurochemistry of gambling, Meyer et al. [46] found that casino gambling (blackjack) increased plasma norepinephrine (NE) and saliva CORT in non-PG subjects. Increased plasma dopamine (DA) was also seen in PG subjects. These effects were accompanied by elevations in $\mathrm{HR}$, a peripheral index associated with subjective reinforcing effects of drugs [47-49]. The NE and HR effects were more pronounced and persistent in PG than in non-PG subjects. Within the GAS framework, Resistance indicates the operation of compensatory responses (see Fig. 1), many of which are opposite in direction to the acute effects of the reinforcer [50]. 
Therefore, greater neurochemical response during gambling may coincide with greater neurochemical deficits in the absence of gambling.

In a sample of males with moderate PG (17.5 out of 40 on the PG version of the Yale-Brown Obsessive Compulsive Scale; PG-YBOCS [51]), mean baseline CORT levels were higher than in healthy male controls; however, within the PG group, CORT levels correlated negatively with PG severity on the PG-YBOCS [52•]. In a mixed-gender sample, the rise of CORT in the first $30 \mathrm{~min}$ after awakening was greater in problem gamblers (1-4 DSM-IV PG criteria; mean=1.97 out of 10) and PGs (5-10 DSM-IV PG criteria; mean=6.27 out of 10) than in recreational gamblers (0 DSM-IV PG criteria) [53•]. The authors suggested this pattern may reflect allostatic overload due to chronic life stressors. Elevated CORT response in the absence of an acute stressor suggests that these subjects were in the intermediate stages of the GAS (Fig. 1; "Alarm"/"Resistance"). This is consistent with their moderate overall levels of symptom severity. At the same time, the negative correlation between CORT and PG-YBOCS scores and in the male PG sample is consistent with the progressive decline in baseline stress system function in individuals with more severe PG (Fig. 1; "Exhaustion").

CORT levels correlate positively with ventral striatal response to monetary vs. erotic cues in PG subjects but not in controls [54••]. This linkage is noteworthy given that CORT and DA responses to amphetamine are positively correlated and linked with greater euphoric effects in healthy subjects [55]. Thus, signals for monetary reward appear to evoke a stimulant-like pattern of neurochemical responses in $\mathrm{PG}$ subjects.

Baseline plasma levels of the NE metabolite, 3-methoxy-4hydroxyphenylglycol (MHPG), are also elevated in PG subjects (indicating greater central NE turnover) vs. controls [56]. Baseline levels of the DA metabolite, homovanillic acid (HVA), are also significantly greater in PG subjects vs. controls [57], in line with the selective increase in DA during blackjack seen in PG subjects [46]. Both effects are consistent with a chronic stress-like syndrome in PG.

Several procedures have been used to assess stress-like responses to gambling in the laboratory. Data from these tasks are mixed, as might be expected, given the range of factors that could influence response. The potential for a meaningful (rather than token) loss has been cited as a critical feature of gambling that is missing from most experimental models [58]. Evidence from healthy subjects seems to support this possibility: College students who wager course participation credits on the outcome of a videotaped horse race display greater elevations in HR and subjective excitement than students who choose not to wager (although self-selection may contribute to this difference) [59]. In the absence of risk, both a generic arousing stimulus (e.g., videotape of a roller coaster ride) and a gambling-related stimulus (e.g., videotape of winning at gambling) evoke craving to gamble in active PG subjects but not in abstinent PG subjects or controls [60]. Thus, arousal per se may increase the incentive value of gambling, but only if the somatic marker is perceived as a signal for reward rather than threat.

In non-problematic gamblers, increasing autonomic arousal via bursts of white noise leads to increased bet size on an EGM; conversely, in problematic gamblers, noise reduces bet size [11]. In healthy subjects, noise impairs cognitive control (i.e., decreases feedback-related negativity) and promotes risky decision-making [61]. This effect coincides with decreased activation in the anterior cingulate cortex. Healthy subjects who receive occasional auditory "stop signals" during a gambling task display decreased preference for risky response options [62]. Stop signals elicit P300 — an electrophysiological index of the brain's processing of conceptual novelty or discrepancy $[63,64]$. P300 is mediated by phasic release of NE from locus coeruleus neurons that project to the prefrontal cortex [65]. Acute stress has a similar effect in animals [66] but over time downregulates post-synaptic alpha-2 NE receptors that inhibit sympathetic responses [67]. Thus, downregulation of postsynaptic alpha-2 NE receptors would initially be expected to disinhibit sympathetic responses to stress-induced NE release in PG subjects (Fig. 1; "Resistance").

In substance-dependent individuals, stress reliably increases craving for the preferred substance [68••]. In contrast, Steinberg et al. [69] found that stress induced by uncontrollable noise significantly decreased desire to gamble in male PG subjects with and without co-occurring alcohol dependence. Uncontrollable noise also coincided with significantly lower systolic blood pressure (BP) in subjects with PG but increased $\mathrm{BP}$ in non-PG subjects with alcohol dependence or healthy controls. In all groups, uncontrollable noise increased desire for alcohol, supporting the effectiveness of the stressor. Thus, acute stress selectively decreases the incentive value of gambling in subjects with PG. This result is consistent with a homeostatic effect in individuals chronically exposed to gambling. The lack of this effect on alcohol craving in non-PG alcohol-dependent subjects, who presumably have also undergone allostasis [70], suggests that alcohol may serve a different role in alcohol dependence (e.g., stress dampening [71]) than gambling does in PG (e.g., stress enhancing).

It should be noted that response to a behavioral stressor (breath holding plus mental arithmetic) has been found to distinguish between PG subjects who were able to achieve sustained abstinence vs. PG subjects who relapsed quickly [72]. In this case, greater distress was found in the rapid relapsing subjects, which runs counter to the homeostatic interpretation of the noise stress data. However, desire to gamble was not assessed in the breath holding/arithmetic study, so whether relapse-related differences reflected increased gambling motivation from stress itself or from a delayed reduction in arousal (i.e., compensatory rebound) is unclear. The latter 
possibility is supported by research [73] showing that craving to gamble in PG subjects is most often "related to an unpleasant dearousing [sic] state" (p. 1555).

\section{Neurobiological Basis of Homeostatic Effects in PG Subjects}

Clonidine Drug challenge studies can define the role of specific neurochemical substrates in human subjects. Using this strategy, Pallanti and colleagues found that the alpha-2 NE agonist, clonidine, caused significantly less growth hormone release in PG subjects than in healthy controls [74]. This indicated hypofunctional post-synaptic alpha-2 NE receptors, which the authors suggested may stem from "noradrenergic overdrive" (i.e., during gambling activity). Lower responses also correlated with greater PG severity, consistent with a progressive decline in alpha-2 NE function with more exposure to gambling. Stimulation of post-synaptic alpha-2 NE receptors by clonidine leads to hypotension [75]. Thus, stimulation of hypofunctional post-synaptic alpha-2 receptors may have mediated the stress-related decrease in BP in PG subjects in Steinberg et al.'s [69] study.

Yohimbine The alpha-2 NE antagonist, yohimbine, has been described as a pharmacological stressor [76]. This drug can increase anxiety and craving for alcohol in alcohol-dependent subjects [77, 78]. A functional magnetic resonance imaging (fMRI) study found that a modest dose of yohimbine (0.2$0.3 \mathrm{mg} / \mathrm{kg}$ ) activated the amygdala in PG subjects $(n=4)$ but not in controls $(n=5)[79 \bullet \cdot$. The drug enhanced subjective distress in both groups, with a trend toward a greater increase in PGs. However, yohimbine did not increase craving to gamble in either group and in fact led to a non-significant decrease in craving in PG subjects (Cohen's $d=0.33$ ). By blocking presynaptic autoreceptors, yohimbine removes feedback inhibition and increases NE release. In the absence of an environmental stressor, such an effect would preferentially increase tonic NE and engage post-synaptic alpha-2 NE receptors (especially at the modest dose used in this study). Another fMRI study found that, during expectation of reward, PG subjects display a severity-dependent decrease in activation of the amygdala [80]. NE release in the amygdala mediates inhibitory avoidance learning, and this effect is enhanced by blockade of alpha-2 NE autoreceptors (i.e., yohimbine should enhance inhibitory avoidance) [81]. Collectively, the evidence suggests that PG subjects may be hyposensitive to NE signals (somatic markers) that serve to deter risky decisions during gambling and that disinhibition of NE release by yohimbine might reinstate this deterrent effect.

Amphetamine Amphetamine (specifically, $d$-amphetamine) activates NE, CORT, and DA and is a standard tool for testing drug-based reward in humans. A recent positron-emission tomography (PET) study found significantly greater amphetamine-induced dorsal striatal DA release in male PG subjects (mean age $=33$ ) with clinically relevant PG severity (mean South Oaks Gambling Screen $(\mathrm{SOGS})=12$; above the normative mean for treatment-seeking PG patients [82]) vs. healthy male controls (mean age $=35$, SOGS $=0$ ) $[83 \bullet \bullet]$. Amphetamine led to equivalent mean DA release in the two groups in the ventral striatum. However, DA release in this region correlated positively with symptom severity in the PG group. Although NE was not assessed, HR and BP responses to amphetamine, which are primarily mediated by NE [84], were recorded. Amphetamine led to a persistent increase in diastolic BP during the later stages of the dose in PG subjects but not in controls [85••], consistent with possibly hypersensitive alpha-1 NE receptors in the former group [86]. A marked, severity-dependent decline in HR that closely mirrored the BP elevation at this time appeared to reflect a compensatory response, due possibly to hypofunctional beta receptors [86], in PG subjects. Lastly, PG subjects displayed lower baseline CORT levels than controls did, and this deficit was partly reversed by amphetamine. Lower baseline CORT in this relatively severe PG sample is consistent with the negative correlation observed between CORT levels and severity on the PG-YBOCS in the male PG sample described above [52•].

The PET scan data suggest that chronic exposure to gambling is associated with increased DA system reactivity, decreased basal CORT response, and compensatory NE receptor changes in $P G$ subjects compared to controls. The elevated DA response in PG subjects is consistent with sensitization, although the possibility that this hyper-reactivity predated chronic gambling exposure cannot be ruled out. The elevated BP, decrease in HR, and overall deficit in basal CORT are consistent with allostasis, although again, a causal role for gambling cannot be established. Given that the PET, cardiovascular, and CORT effects all emerged in the same subjects, it is possible that the DA, NE, and HPA responses are functionally related. That is, sensitization-like and allostasis-like responses in PG subjects may be opposite sides of the same coin.

\section{A Mechanistic Explanation for Catecholamine and HPA Disturbances in PG}

NE plays an important role in sensitization to amphetamine [87]. DA transmission increases in the striatum when rats receive an alpha-2 NE antagonist [88], "consistent with a tonic inhibition of dopamine release by alpha (2) adrenergic receptors" (p. 654). Alpha-2 NE and glucocorticoid receptors also have reciprocal inhibitory effects [89]. Thus, downregulation of 
alpha-2 NE receptors could disinhibit HPA responses (i.e., increase acute CORT response to stress or gambling), causing a positive feedback cycle of stress dysregulation. Repeated exposure to amphetamine leads to upregulation of alpha-1 NE receptors [90]. Conversely, blockade of alpha-1 receptors prevents the development of amphetamine sensitization [91]. Thus, downregulation of alpha-2 and upregulation of alpha-1 NE receptors would each be expected to facilitate increased DA response to amphetamine in PG subjects. In healthy controls, CORT response to an environmental stressor correlates with amphetamine-induced DA release in the ventral striatum [92]. In subjects with a history of chronic stress, an acute stressor causes an increase in ventral striatal DA that correlates $(r \sim 0.80)$ with the increase in salivary CORT [93]. Thus, alpha- 2 NE receptors are negatively coupled with DA release, whereas alpha-1 and CORT are positively coupled to DA release in response to amphetamine and stress, respectively.

If the pattern of neurochemical anomalies seen in PG subjects is a result of chronic exposure to gambling, it should be possible to specify the neural events that occur during gambling that give rise to these anomalies. That is, it should be possible to go beyond the nominal explanation of "stress" as the causal agent, to a mechanism-based explanation.

Delivery of a stimulus, whose value is better than expected, results in phasic (pulsatile) DA release from striatal DA neurons. This event is referred to as a "reward prediction error" and is believed to confer incentive salience to the events (i.e., conditioned cues) that immediately preceded it [94]. Reward prediction errors guide future behavior by promoting approach responses to salient stimuli. Because the occurrence and magnitude of reward in gambling are never fully predicted, every win should evoke a reward prediction error, with corresponding DA release, cf. [95].

Gambling also involves unpredictable reward omission and loss. Preuschoff et al. [96] proposed that omission of expected reward leads to a risk prediction error, reflecting a discrepancy between the perceived likelihood vs. occurrence of reward omission. It should be noted that a risk prediction error differs from a negative prediction error arising from omission of reward. Negative prediction errors reflect the occurrence of an outcome that is expected (perceived as possible) but not desirable. Such errors may be associated with disappointment or frustration. Risk prediction errors reflect the occurrence of an outcome that is not expected (perceived as impossible or improbable, or not anticipated at all) and not desirable. Such errors may be associated with unpleasant surprise or disbelief. Since all gamblers hope to win but, on average, the house always wins, gamblers may experience more risk prediction errors than reward expectancy errors. However, since the potential for a win capable of erasing all losses exists on every bet (on a slot machine), and more sensory events (e.g., bells, lights) usually accompany a win than a loss, reward omission may be less salient than reward delivery and, thus, less likely to guide behavior. Nevertheless, the brain registers reward omission/risk prediction error as evidenced by phasic dilation of the pupil [96]. Furthermore, brain stem NE neurons code risk prediction errors via phasic activation of post-synaptic alpha-2 NE receptors that cause pupil dilation [97].

Chronic exposure to reward prediction errors while gambling may promote sensitization [98, 99]. Similarly, chronic exposure to risk prediction errors could induce neuroadaptations. As noted above, PG subjects exhibit severity-dependent deficits in post-synaptic alpha-2 receptor function [74], consistent with progressive downregulation. Whereas alpha-2 NE receptor antagonists block pupil dilation, alpha-1 NE antagonists potentiate this reflex [100]. Upregulation of alpha-1 NE receptors should have the opposite effect (i.e., should inhibit the pupil dilation reflex). Increased alpha-1 receptor function, suggested by the persistent elevation of diastolic BP following amphetamine in PG subjects [85••], may thus represent a compensatory response designed to minimize the disruptive effects of ongoing exposure to risk prediction errors during gambling.

In summary, downregulation of alpha-2 NE receptors can disinhibit HPA responses, leading to progressive stress dysregulation and eventual allostatic overload. Downregulation of alpha-2 and upregulation alpha-1 NE receptors can also disinhibit and augment DA release, respectively, promoting sensitization. In this way, ongoing exposure to unpredictable rewards and losses can lead to a vicious cycle of escalating incentive motivation to gamble and concomitant impairment of the brain's ability to adapt to the stress of mounting losses.

\section{Conclusion}

This article provides a selective review of key findings on stress and gambling. It is intended to offer a framework for testing hypotheses and developing ways to prevent or treat PG by targeting stress. Comorbidity, gender, motives for gambling, and preferred activities can all influence stress-related aspects of PG. Future research on these factors may help to explain variability in stress response and inform personalized interventions for different individuals with $\mathrm{PG}$.

\section{Compliance with Ethics Guidelines}

Conflict of Interest Candice Biback and Martin Zack declare that they have no conflict of interest.

Human and Animal Rights and Informed Consent This article does not contain any studies with human or animal subjects performed by any of the authors. 


\section{References}

Papers of particular interest, published in the past 3 years, have been highlighted as:

- Of importance

- Of major importance

1. Selye H. The stress of life. New York: McGraw-Hill; 1956.

2. Taylor S, Sirois F. Health psychology. 2nd ed. Vancouver: McGraw-Hill-Ryerson; 2012.

3. Koob GF, Le Moal M. Drug addiction, dysregulation of reward, and allostasis. Neuropsychopharmacology. 2001;24(2):97-129. doi:10.1016/S0893-133X(00)00195-0.

4. Enoch MA. The role of early life stress as a predictor for alcohol and drug dependence. Psychopharmacology (Berl). 2010;214(1): 17-31. doi:10.1007/s00213-010-1916-6.

5. Sinha R, Shaham Y, Heilig M. Translational and reverse translational research on the role of stress in drug craving and relapse. Psychopharmacology (Berl). 2011;218(1):69-82. doi:10.1007/ s00213-011-2263-y.

6. A.P.A. Diagnostic and statistical manual of mental disorders. 5th ed. Arlington: American Psychiatric Publishing; 2013.

7. Frascella J, Potenza MN, Brown LL, Childress AR. Shared brain vulnerabilities open the way for nonsubstance addictions: carving addiction at a new joint? Ann N Y Acad Sci. 2010;1187:294-315. doi:10.1111/j.1749-6632.2009.05420.x.

8. Gomes K, Pascual-Leone A. A resource model of change: client factors that influence problem gambling treatment outcomes. J Gambl Stud. 2014. doi:10.1007/s10899-014-9493-y.

9. Nastally BL, Dixon MR. Adolescent gambling: current trends in treatment and future directions. Int $\mathrm{J}$ Adolesc Med Health. 2010;22(1):95-111.

10. Lee GP, Storr CL, Ialongo NS, Martins SS. Association between adverse life events and addictive behaviors among male and female adolescents. Am J Addict. 2012;21(6):516-23. doi:10.1111/ j.1521-0391.2012.00285.x.

11. Rockloff MJ, Signal T, Dyer V. Full of sound and fury, signifying something: the impact of autonomic arousal on EGM gambling. J Gambl Stud. 2007;23(4):457-65. doi:10.1007/s10899-007-9061-9.

12. Baudinet J, Blaszczynski A. Arousal and gambling mode preference: a review of the literature. J Gambl Stud. 2012;29(2):343-58. doi:10.1007/s10899-012-9304-2.

13. Sharpe L. Patterns of autonomic arousal in imaginal situations of winning and losing in problem gambling. J Gambl Stud. 2004;20(1):95-104. doi:10.1023/B:JOGS.0000016706.96540.43.

14. Milkman HB, Sunderwirth SG. Craving for ecstasy and natural highs: a positive approach to mood alteration. Thousand Oaks: Sage; 2010

15. George O, Le Moal M, Koob GF. Allostasis and addiction: role of the dopamine and corticotropin-releasing factor systems. Physiol Behav. 2011;106(1):58-64. doi:10.1016/j.physbeh.2011.11.004.

16. Koolhaas JM, Bartolomucci A, Buwalda B, de Boer SF, Flugge G, Korte SM, et al. Stress revisited: a critical evaluation of the stress concept. Neurosci Biobehav Rev. 2011;35(5):1291-301. doi:10. 1016/j.neubiorev.2011.02.003

17. Gainsbury SM, Russell A, Blaszczynski A, Hing N. The interaction between gambling activities and modes of access: a comparison of Internet-only, land-based only, and mixed-mode gamblers. Addict Behav. 2014;41:34-40. doi:10.1016/j.addbeh.2014. 09.023 .

18. Ferguson CJ, Coulson M, Barnett J. A meta-analysis of pathological gaming prevalence and comorbidity with mental health, academic and social problems. J Psychiatr Res. 2011;45(12):1573-8. doi:10.1016/j.jpsychires.2011.09.005.
19. McBride O, Adamson G, Shevlin M. A latent class analysis of DSM-IV pathological gambling criteria in a nationally representative British sample. Psychiatry Res. 2010;178(2):401-7. doi:10. 1016/j.psychres.2009.11.010.

20. Preston SD, Buchanan TW, Stansfield RB, Bechara A. Effects of anticipatory stress on decision making in a gambling task. Behav Neurosci. 2007;121(2):257-63.

21. Santos-Ruiz A, Garcia-Rios MC, Fernandez-Sanchez JC, PerezGarcia M, Munoz-Garcia MA, Peralta-Ramirez MI. Can decisionmaking skills affect responses to psychological stress in healthy women? Psychoneuroendocrinology. 2012;37(12):1912-21. doi: 10.1016/j.psyneuen.2012.04.002.

22. Buckert M, Schwieren C, Kudielka BM, Fiebach CJ. Acute stress affects risk taking but not ambiguity aversion. Front Neurosci. 2014;8:82. doi:10.3389/fnins.2014.00082.

23. Putman P, Antypa N, Crysovergi P, van der Does WA. Exogenous cortisol acutely influences motivated decision making in healthy young men. Psychopharmacology (Berl). 2010;208(2):257-63. doi:10.1007/s00213-009-1725-y.

24. Koot S, Baars A, Hesseling P, van den Bos R, Joels M. Timedependent effects of corticosterone on reward-based decisionmaking in a rodent model of the Iowa Gambling Task. Neuropharmacology. 2013;70:306-15. doi:10.1016/j. neuropharm.2013.02.008.

25. Clark L, Li R, Wright CM, Rome F, Fairchild G, Dunn BD, et al. Risk-avoidant decision making increased by threat of electric shock. Psychophysiology. 2012;49(10):1436-43. doi:10.1111/j. 1469-8986.2012.01454.x.

26. Stankovic A, Fairchild G, Aitken MR, Clark L. Effects of psychosocial stress on psychophysiological activity during risky decision-making in male adolescents. Int J Psychophysiol. 2013;93(1):22-9. doi:10.1016/j.ijpsycho.2013.11.001.

27. Bechara A, Tanel D, Damasio A. The somatic marker hypothesis and decision-making. In: Boller F, Grafman J, editors. Handbook of neuropsychology: frontal lobes. Amsterdam: Elsevier; 2002. p. $117-41$.

28. Yerkes RM, Dodson JD. The relation of strength of stimulus to rapidity of habit-formation. J Comp Neurol Psychol. 1908;18: 459-82. doi:10.1002/cne.920180503.

29.• Schmidt B, Mussel P, Hewig J. I'm too calm—let's take a risk! On the impact of state and trait arousal on risk taking. Psychophysiology. 2013;50(5):498-503. doi:10.1111/psyp. 12032. This paper provides evidence of a link between optimum level of arousal, situational sources of arousal, and 'cybernetic' or self-regulatory risk-taking behavior in a gambling paradigm.

30. Fischer T, Langner R, Birbaumer N, Brocke B. Arousal and attention: self-chosen stimulation optimizes cortical excitability and minimizes compensatory effort. J Cogn Neurosci. 2008;20(8): 1443-53. doi:10.1162/jocn.2008.20101.

31. Giddens JL, Xian H, Scherrer JF, Eisen SA, Potenza MN. Shared genetic contributions to anxiety disorders and pathological gambling in a male population. J Affect Disord. 2011;132(3):406-12. doi:10.1016/j.jad.2011.03.008.

32. Najavits LM. Treatment utilization of pathological gamblers with and without PTSD. J Gambl Stud. 2010;26(4):583-92. doi:10. 1007/s10899-010-9179-z.

33. Kessler RC, Hwang I, LaBrie R, Petukhova M, Sampson NA, Winters KC, et al. DSM-IV pathological gambling in the national comorbidity survey replication. Psychol Med. 2008;38(9):135160. doi:10.1017/S0033291708002900.

34. Dowling NA, Cowlishaw S, Jackson AC, Merkouris SS, Francis KL, Christensen DR. Prevalence of psychiatric comorbidity in treatment-seeking problem gamblers: a systematic review and meta-analysis. Austral NZ J Psychiatr. 2015;49(6):519-39. 
35. Hilbert K, Lueken U, Beesdo-Baum K. Neural structures, functioning and connectivity in generalized anxiety disorder and interaction with neuroendocrine systems: a systematic review. J Affect Disord. 2014;158:114-26. doi:10.1016/j.jad.2014.01.022.

36. Vreeburg SA, Zitman FG, van Pelt J, Derijk RH, Verhagen JC, van Dyck R, et al. Salivary cortisol levels in persons with and without different anxiety disorders. Psychosom Med. 2010;72(4):340-7. doi:10.1097/PSY.0b013e3181d2f0c8.

37. Daskalakis NP, Lehrner A, Yehuda R. Endocrine aspects of posttraumatic stress disorder and implications for diagnosis and treatment. Endocrinol Metab Clin North Am. 2013;42(3):503-13. doi: 10.1016/j.ecl.2013.05.004.

38. Sinai C, Hirvikoski T, Nordstrom AL, Nordstrom P, Nilsonne A, Wilczek A et al. Hypothalamic pituitary thyroid axis and exposure to interpersonal violence in childhood among women with borderline personality disorder. Eur J Psychotraumatol. 2014;5. doi: 10.3402/ejpt.v5.23911

39. Breslau N, Koenen KC, Luo Z, Agnew-Blais J, Swanson S, Houts $\mathrm{RM}$, et al. Childhood maltreatment, juvenile disorders and adult post-traumatic stress disorder: a prospective investigation. Psychol Med. 2014;44(9):1937-45. doi:10.1017/S0033291713002651.

40. Dowling NA, Jackson AC, Suomi A, Lavis T, Thomas SA, Patford J, et al. Problem gambling and family violence: prevalence and patterns in treatment-seekers. Addict Behav. 2014;39(12): 1713-7. doi:10.1016/j.addbeh.2014.07.006.

41. Kausch O, Rugle L, Rowland DY. Lifetime histories of trauma among pathological gamblers. Am J Addict. 2006;15(1):35-43. doi:10.1080/10550490500419045.

42. Hodgins DC, Schopflocher DP, el-Guebaly N, Casey DM, Smith GJ, Williams RJ. The association between childhood maltreatment and gambling problems in a community sample of adult men and women. Psychol Addict Behav. 2010;24(3):548-54. doi:10.1037/ a0019946.

43. Ledgerwood DM, Milosevic A. Clinical and personality characteristics associated with post traumatic stress disorder in problem and pathological gamblers recruited from the community. J Gambl Stud. 2013. doi:10.1007/s10899-013-9426-1.

44. Kirkpatrick HA, Heller GM. Post-traumatic stress disorder: theory and treatment update. Int J Psychiatry Med. 2014;47(4):337-46. doi:10.2190/PM.47.4.h.

45. Taber JI, McCormick RA, Ramirez LF. The prevalence and impact of major life stressors among pathological gamblers. Int J Addict. 1987;22(1):71-9.

46. Meyer G, Schwertfeger J, Exton MS, Janssen OE, Knapp W, Stadler MA, et al. Neuroendocrine response to casino gambling in problem gamblers. Psychoneuroendocrinology. 2004;29(10): 1272-80. doi:10.1016/j.psyneuen.2004.03.005.

47. Mendelson JH, Mello NK, Sholar MB, Siegel AJ, Mutschler N, Halpern J. Temporal concordance of cocaine effects on mood states and neuroendocrine hormones. Psychoneuroendocrinology. 2002;27(1-2):71-82.

48. Nelson RA, Boyd SJ, Ziegelstein RC, Herning R, Cadet JL, Henningfield JE, et al. Effect of rate of administration on subjective and physiological effects of intravenous cocaine in humans. Drug Alcohol Depend. 2006;82(1):19-24. doi:10.1016/j. drugalcdep.2005.08.004

49. Conrod PJ, Peterson JB, Pihl RO. Reliability and validity of alcohol-induced heart rate increase as a measure of sensitivity to the stimulant properties of alcohol. Psychopharmacology (Berl). 2001;157(1):20-30.

50. Koob GF. Dynamics of neuronal circuits in addiction: reward, antireward, and emotional memory. Pharmacopsychiatry. 2009;42 Suppl 1:S32-41. doi:10.1055/s-0029-1216356.

51. Pallanti S, DeCaria CM, Grant JE, Urpe M, Hollander E. Reliability and validity of the pathological gambling adaptation of the Yale-Brown Obsessive-Compulsive Scale (PG-
YBOCS). J Gambl Stud. 2005;21(4):431-43. doi:10.1007/ s10899-005-5557-3.

52. Geisel O, Panneck P, Hellweg R, Wiedemann K, Muller CA. Hypothalamic-pituitary-adrenal axis activity in patients with pathological gambling and Internet use disorder. Psychiatry Res. 2015;226(1):97-102. doi:10.1016/j.psychres.2014.11.078.

53. Wohl MJ, Matheson K, Young MM, Anisman H. Cortisol rise following awakening among problem gamblers: dissociation from comorbid symptoms of depression and impulsivity. J Gambl Stud. 2008;24(1):79-90. doi:10.1007/s10899-007-9080-6.

54.• Li Y, Sescousse G, Dreher JC. Endogenous cortisol levels are associated with an imbalanced striatal sensitivity to monetary versus non-monetary cues in pathological gamblers. Front Behav Neurosci. 2014;8:83. doi:10.3389/fnbeh.2014.00083. This paper reports on the ability of cues for monetary reward to co-activate dopamine and the hypothalamic pituitary axis in PG subjects (but not controls), which conforms to the acute effects of amphetamine and suggests a psychostimulant-like effect of gambling in PG.

55. Oswald LM, Wong DF, McCaul M, Zhou Y, Kuwabara H, Choi L, et al. Relationships among ventral striatal dopamine release, cortisol secretion, and subjective responses to amphetamine. Neuropsychopharmacology. 2005;30(4):821-32. doi:10.1038/sj. npp. 1300667.

56. Roy A, Adinoff B, Roehrich L, Lamparski D, Custer R, Lorenz V, et al. Pathological gambling. A psychobiological study. Arch Gen Psychiatry. 1988;45(4):369-73.

57. Bergh C, Eklund T, Sodersten P, Nordin C. Altered dopamine function in pathological gambling. Psychol Med. 1997;27(2): 473-5.

58. Anselme P. Does reward unpredictability reflect risk? Behav Brain Res. 2014;280:119-27. doi:10.1016/j.bbr.2014.12.003.

59. Seifert CA, Wulfert E. The effects of realistic reward and risk on simulated gambling behavior. Am J Addict. 2011;20(2):120-6. doi:10.1111/j.1521-0391.2010.00114.x.

60. Sodano R, Wulfert E. Cue reactivity in active pathological, abstinent pathological, and regular gamblers. J Gambl Stud. 2010;26(1):53-65. doi:10.1007/s10899-009-9146-8.

61. Banis S, Lorist MM. Acute noise stress impairs feedback processing. Biol Psychol. 2012;91(2):163-71. doi:10.1016/j.biopsycho. 2012.06.009.

62. Stevens T, Brevers D, Chambers CD, Lavric A, McLaren IP, Mertens M, et al. How does response inhibition influence decision making when gambling? J Exp Psychol Appl. 2015;21(1):15-36. doi:10.1037/xap0000039.

63. Knyazev GG, Levin EA, Savostyanov AN. A failure to stop and attention fluctuations: an evoked oscillations study of the stopsignal paradigm. Clin Neurophysiol. 2008;119(3):556-67. doi: 10.1016/j.clinph.2007.11.041.

64. Enriquez-Geppert S, Konrad C, Pantev C, Huster RJ. Conflict and inhibition differentially affect the N200/P300 complex in a combined go/nogo and stop-signal task. Neuroimage. 2010. doi:10. 1016/j.neuroimage.2010.02.043.

65. Nieuwenhuis S, Heslenfeld DJ, von Geusau NJ, Mars RB, Holroyd CB, Yeung N. Activity in human reward-sensitive brain areas is strongly context dependent. Neuroimage. 2005;25(4): 1302-9.

66. Arnsten AF, Li BM. Neurobiology of executive functions: catecholamine influences on prefrontal cortical functions. Biol Psychiatry. 2005;57(11):1377-84. doi:10.1016/j.biopsych.2004. 08.019 .

67. Cancela LM, Volosin M, Molina VA. Chronic stress attenuation of alpha 2-adrenoceptor reactivity is reversed by naltrexone. Pharmacol Biochem Behav. 1988;31(1):33-5.

68.• Sinha R. The clinical neurobiology of drug craving. Curr Opin Neurobiol. 2013;23(4):649-54. doi:10.1016/j.conb.2013.05.001. 
This paper describes the critical role of arousal in craving states and how disturbances in the modulatory role of the prefrontal cortex on limbic-striatal circuitry encourage seeking of addictive reinforcers.

69. Steinberg L, Tremblay AM, Zack M, Busto UE, Zawertailo LA. Effects of stress and alcohol cues in men with and without problem gambling and alcohol use disorder. Drug Alcohol Depend. 2011;119(1-2):46-55. doi:10.1016/j.drugalcdep.2011.05.011.

70. Koob GF. Alcoholism: allostasis and beyond. Alcohol Clin Exp Res. 2003;27(2):232-43. doi:10.1097/01.ALC.0000057122. 36127.C2.

71. Hefner KR, Curtin JJ. Alcohol stress response dampening: selective reduction of anxiety in the face of uncertain threat. $\mathrm{J}$ Psychopharmacol. 2011;26(2):232-44. doi:10.1177/ 0269881111416691.

72. Daughters SB, Lejuez CW, Strong DR, Brown RA, Breen RB, Lesieur HR. The relationship among negative affect, distress tolerance, and length of gambling abstinence attempt. J Gambl Stud. 2005;21(4):363-78.

73. de Castro V, Fong T, Rosenthal RJ, Tavares H. A comparison of craving and emotional states between pathological gamblers and alcoholics. Addict Behav. 2007;32(8):1555-64. doi:10.1016/j. addbeh.2006.11.014.

74. Pallanti S, Bernardi S, Allen A, Chaplin W, Watner D, DeCaria $\mathrm{CM}$, et al. Noradrenergic function in pathological gambling: blunted growth hormone response to clonidine. J Psychopharmacol. 2010;24(6):847-53. doi:10.1177/ 0269881108099419.

75. Gregoretti C, Moglia B, Pelosi P, Navalesi P. Clonidine in perioperative medicine and intensive care unit: more than an antihypertensive drug. Curr Drug Targets. 2009;10(8):799-814.

76. See RE, Waters RP. Pharmacologically-induced stress: a crossspecies probe for translational research in drug addiction and relapse. Am J Transl Res. 2010;3(1):81-9.

77. Krystal JH, Webb E, Cooney NL, Kranzler HR, Southwick SW, Heninger GR, et al. Serotonergic and noradrenergic dysregulation in alcoholism: m-chlorophenylpiperazine and yohimbine effects in recently detoxified alcoholics and healthy comparison subjects. Am J Psychiatry. 1996;153(1):83-92.

78. Umhau JC, Schwandt ML, Usala J, Geyer C, Singley E, George DT, et al. Pharmacologically induced alcohol craving in treatment seeking alcoholics correlates with alcoholism severity, but is insensitive to acamprosate. Neuropsychopharmacology. 2011;36(6): 1178-86. doi:10.1038/npp.2010.253.

79.• Elman I, Becerra L, Tschibelu E, Yamamoto R, George E, Borsook D. Yohimbine-induced amygdala activation in pathological gamblers: a pilot study. PLoS One. 2012;7(2):e31118. doi:10. 1371/journal.pone.0031118PONE-D-11-10891. This paper describes the differential effects of the pharmacological stressor, yohimbine on amygdala response and subjective effects in PG subjects and controls.

80. van Holst RJ, Veltman DJ, Buchel C, van den Brink W, Goudriaan AE. Distorted expectancy coding in problem gambling: is the addictive in the anticipation? Biol Psychiatry. 2012;71(8):741-8. doi:10.1016/j.biopsych.2011.12.030.

81. Ferry B, Parrot S, Marien M, Lazarus C, Cassel JC, McGaugh JL. Noradrenergic influences in the basolateral amygdala on inhibitory avoidance memory are mediated by an action on alpha2adrenoceptors. Psychoneuroendocrinology. 2015;51:68-79. doi: 10.1016/j.psyneuen.2014.09.010.

82. Stinchfield R. Reliability, validity, and classification accuracy of the South Oaks Gambling Screen (SOGS). Addict Behav. 2002;27(1):1-19.

83.• Boileau I, Payer D, Chugani B, Lobo DS, Houle S, Wilson AA, et al. In vivo evidence for greater amphetamine-induced dopamine release in pathological gambling: a positron emission tomography study with [C]-(+)-PHNO. Mol Psychiatry. 2013. doi:10.1038/mp. 2013.163. This paper demonstrated significantly greater dopamine release in response to amphetamine challenge in men with PG compared to healthy male controls, suggesting possible sensitization of brain reward pathways.

84. Nurnberger Jr JI, Simmons-Alling S, Kessler L, Jimerson S, Schreiber J, Hollander E, et al. Separate mechanisms for behavioral, cardiovascular, and hormonal responses to dextroamphetamine in man. Psychopharmacology (Berl). 1984;84(2):200-4.

85.• Zack M, Boileau I, Payer D, Chugani B, Lobo D, Houle S. Differential cardiovascular and hypothalamic pituitary response to amphetamine in male pathological gamblers versus healthy controls. J Psychopharmacol. 2015. This paper demonstrated a disturbance in HPA- and norepinephrine-mediated neuroendocrine and physiological responses to amphetamine challenge in males with PG compared to healthy male controls, suggesting possible allostasis of stress circuitry.

86. Schindler CW, Zheng JW, Tella SR, Goldberg SR. Pharmacological mechanisms in the cardiovascular effects of methamphetamine in conscious squirrel monkeys. Pharmacol Biochem Behav. 1992;42(4):791-6.

87. Weinshenker D, Miller NS, Blizinsky K, Laughlin ML, Palmiter RD. Mice with chronic norepinephrine deficiency resemble amphetamine-sensitized animals. Proc Natl Acad Sci U S A. 2002;99(21):13873-7. doi:10.1073/pnas.212519999.

88. Rominger A, Mille E, Boning G, Wangler B, Josef Gildehaus F, Arszol C, et al. Alpha2-adrenergic drugs modulate the binding of [18F] fallypride to dopamine D2/3 receptors in striatum of living mouse. Synapse. 2010;64(8):654-7. doi:10.1002/syn.20785.

89. Flugge G. Effects of cortisol on brain alpha2-adrenoceptors: potential role in stress. Neurosci Biobehav Rev. 1999;23(7): 949-56.

90. Cools AR. Differential role of mineralocorticoid and glucocorticoid receptors in the genesis of dexamphetamine-induced sensitization of mesolimbic, alpha 1 adrenergic receptors in the ventral striatum. Neuroscience. 1991;43(2-3):419-28.

91. Drouin C, Blanc G, Villegier AS, Glowinski J, Tassin JP. Critical role of alpha1-adrenergic receptors in acute and sensitized locomotor effects of D-amphetamine, cocaine, and GBR 12783: influence of preexposure conditions and pharmacological characteristics. Synapse. 2002;43(1):51-61. doi:10.1002/syn.10023.

92. Wand GS, Oswald LM, McCaul ME, Wong DF, Johnson E, Zhou $\mathrm{Y}$, et al. Association of amphetamine-induced striatal dopamine release and cortisol responses to psychological stress. Neuropsychopharmacology. 2007;32(11):2310-20. doi:10.1038/ sj.npp.1301373.

93. Pruessner JC, Champagne F, Meaney MJ, Dagher A. Dopamine release in response to a psychological stress in humans and its relationship to early life maternal care: a positron emission tomography study using [11C] raclopride. J Neurosci. 2004;24(11): 2825-31. doi:10.1523/JNEUROSCI.3422-03.2004.

94. Schultz W. Predictive reward signal of dopamine neurons. J Neurophysiol. 1998;80(1):1-27.

95. Redish AD. Addiction as a computational process gone awry. Science. 2004;306(5703):1944-7. doi:10.1126/science.1102384.

96. Preuschoff K, Hart BM, Einhauser W. Pupil dilation signals surprise: evidence for noradrenaline's role in decision making. Front Neurosci. 2011;5:115. doi:10.3389/fnins.2011.00115.

97. Palmeri A, Restivo DA, Casabona A. Involvement of the noradrenergic system in modulating the blink reflex in humans. Brain Res. 2000;867(1-2):210-6.

98. Zack M, Featherstone RE, Mathewson S, Fletcher PJ. Chronic exposure to a gambling-like schedule of reward predictive stimuli can promote sensitization to amphetamine in rats. Front Behav Neurosci. 2014;8:36. doi:10.3389/fnbeh.2014.00036. 
99. Singer BF, Scott-Railton J, Vezina P. Unpredictable saccharin reinforcement enhances locomotor responding to amphetamine. Behav Brain Res. 2012;226(1):340-4. doi:10. 1016/j.bbr.2011.09.003.
100. Hey JA, Koss MC. Alpha 1- and alpha 2-adrenoreceptor antagonists produce opposing mydriatic effects by a central action. $\mathrm{J}$ Auton Pharmacol. 1988;8(3):229-39. 